J. Lake Sci. (湖泊科学), 2007, 19(6):705-709

http://www. jlakes.org. E-mail:jlakes@ niglas. ac.cn

(c) 2007 by Journal of Lake Sciences

\title{
水文周期对纳帕海高原湿地草甸土壤碳素的影响”
}

\author{
张 昆 ${ }^{1}$, 田 昆 ${ }^{1 * *}$, 莫剑锋 ${ }^{2}$, 常凤来 ${ }^{3}$, 陆 梅 ${ }^{1}$, 李宁云 4 \\ ( 1 : 西南林学院 环境科学与工程系, 昆明 650224) \\ (2:广西壮族自治区林业勘测设计院, 南宁 530011) \\ (3: 昆明市盘龙区档案局, 昆明 650021$)$ \\ (4:云南省林业科学院, 昆明 650204)
}

摘 要: 综合降水量、蒸发能力、周边高山冰雪融水以及地下水资源的季节性变化特点分析了纳帕海湿地草甸水文周期特 征, 采用野外采样和室内分析相结合的方法, 研究了水文周期对草甸土壤有机质变化的影响. 结果表明, 纳帕海湿地水文 特征中草甸水位的周期性变化显著,并且水文周期对纳帕海湿地的草甸土壤有机质影响显著,其有机质变化表现为在 0 $-20 \mathrm{~cm}$ 土层呈不规则的 “W” 型多峰曲线变化, 而在 20-40 cm 土层有机质的变化则为不规则的 “ $N$ ” 型. 水文周期变化对 草甸土壤有机质的驱动过程可采用高斯多峰模型模拟,且拟合效果较为理想.

关键词: 纳帕海; 草甸; 水文周期;湿地土壤

\section{Impacts of hydrological periods on organic matters in Napahai wetlands}

ZHANG Kun ${ }^{1}$, TIAN Kun ${ }^{1}$, MO Jianfeng ${ }^{2}$, CHANG Fenglai ${ }^{3}$, LU Mei ${ }^{1} \&$ LI Ningyun ${ }^{4}$

(1: Department of Environmental Science and Engineering, Southwest Forestry College,Kunming 650224, P. R. China)

(2: Guangxi Forestry Inventory and Planning Institute, Nanning 530011, P. R. China)

(3: Panlongqu Archives Bureau, Kunming 650021, P. R. China)

(4: Yunnan Academy of Forestry, Kunming 650204,P. R. China)

\begin{abstract}
Characteristics of hydrology periods was analyzed according to the seasonal characteristics of precipitation, evaporation, dissolved snow and groundwater, and impacts of seasonal hydrological periods on soil organic matters were studied based on field investigation and laboratory analysis in the meadows of Napahai wetlands. The results showed that water level fluctuated greatly in the meadows and soil organic matters were driven greatly by seasonal hydrology periods. Dynamics of organic matters in $0-20 \mathrm{~cm}$ layer appeared in an anomalous "W" shape while "N" shape in $20-40 \mathrm{~cm}$ layer. The driving processes of soil organic matters in the meadows can be fitted in Gaussian model.
\end{abstract}

Keywords : Napahai wetlands; meadows; hydrological periods; wetlands soil

碳是湿地土壤中一种关键的生源要素, 是湿地生态系统中极为重要的生态因子 ${ }^{[1]}$, 又是全球变化的敏 感指示物, 它能够用来指示对气候变化的响应 ${ }^{[2]}$. 湿地作为一种由陆地系统和水体系统相互作用形成的自 然综合体 ${ }^{[3]}$, 水文是影响湿地形成、发育以及维持其结构和功能的首要环境因子, 是湿地过程最重要的决 定因素 ${ }^{[4-7]}$. 目前国内外对湿地土壤碳素的研究大多集中在其背景值的揭示以及空间分布的普遍规律上, 但并未见探讨水文过程对湿地土壤元素驱动作用的相关研究报道. 因此,进行湿地水文周期对湿地土壤碳 素变化的影响研究, 将有助于湿地生态系统动力学研究的深人以及更深人地理解湿地生态过程和功能, 可

* 国家重点基础研究发展 (973) 计划项目(2003CB415100), 云南省环境科学与工程创新人才联合培养基地资助项目 (A3003015) 和云南省林业厅云南高原湿地保护区功能分区研究项目 (200612) 联合资助. 2006-12-20 收稿; $2007-01-18$ 收修改稿. 张昆,男,1981 年生,硕士研究生; E-mail: zhkunlx@ 163.com.

** 通讯作者. 
为进一步研究退化湿地水文的恢复、湿地的优化管理以及可持续发展模式与对策提供科学依据.

\section{1 研究区域及研究方法}

\section{1 试验地生态环境特征}

纳帕海湿地位于滇西北香格里拉县城西部的纳帕海自然保护区内, 为国际重要湿地, 是一低纬度高海 拔的季节性内陆高原湖泊湿地, 面积为 $3760.4 \mathrm{hm}^{2}$, 与长江中下游湖泊湿地、北方平原湿地以及若尔盖高原 湿地有所区别, 其发育于夷平面陷落部分, 周围被海拔 3800-4449 m 的高山包围, 相对孤立狭小, 因而其生 态环境极为脆弱, 为我国湿地的独特类型 ${ }^{[8,9]}$. 纳帕海湿地地处青藏高原的东南延伸部分, 独具高寒、年均 温低、霜期长、降水少、干湿季分明、冬春季干旱突出、气温年较差和日较差大以及冬季漫长而寒冷等特点, 其年均温为 $5.4^{\circ} \mathrm{C}$, 由于地处滇西北迪庆高原少雨区, 其年降水量仅为 $619.9 \mathrm{~mm}$, 且多集中在 $6-8$ 月. 介 于高地和湿草甸过渡地带的草甸面积近 $510 \mathrm{hm}^{2[10]}$, 是纳帕海湿地的主要景观类型, 草甸植物种类丰富, 矮 羊茅 (Festuca coelestis)、滨发草 (Deschampsia littoralis) 和银叶委陵菜 (Potentilla leuconota) 等为优势植物. 由 于纳帕海是一季节性高原湖泊湿地, 草甸区域的地下水位变化较大,在雨季, 其地表有积水, 在干旱的 11 月 至次年 5 月草甸则为冰雪覆盖.

\section{2 研究方法}

通过对研究区域生态环境特征的实地考察和相关资料的收集,选取生境条件一致的区域共设置 7 个样 点,于 2003 年 3 月、 6 月、 8 月、 10 月以及 2004 年 1 月份利用原状土取土器取样 ${ }^{[11,12]}, 3$ 次重复, 采回的取土 管原状土按 0-20 cm 及 20-40 cm 分层. 所采集的样品带回实验室后自然风干,去除石块、残根等杂物, 磨 碎, 过 $0.25 \mathrm{~mm}$ 孔耖, 装袋备用待测. 有机质测定采用重铬酸钾法 ${ }^{[13]}$. 运用 SPSS 11.5、Origin 7.5 和 Excel 2003 等软件对数据进行统计分析处理以及制图.

\section{2 结果与讨论}

\section{1 纳帕海湿地草甸水文周期变化特征}

由于地处滇西北迪庆高原少雨区,且受西南季风、西风带南支以及西太平洋副高的综合影响,纳帕海湿 地全年降水少且分配不均, 7、8 月份月均降水可高达 $152 \mathrm{~mm}$, 而 10 月至次年 5 月降水总量却不足 $150 \mathrm{~mm}$, 年蒸发能力达 $1706.3 \mathrm{~mm}$, 为年降水量的近 3 倍, 尤其是全年最干旱的 $12 、 1$ 月份, 月均蒸发能力达到降水量 的 20 倍之多 (图 1). 来自四周被海拔高达 3800-4449 $\mathrm{m}$ 的高山上的冰雪融水是纳帕海湿地水体的又一补 给源, 5 月份, 该区域气温明显回暖, 受其影响, 高山上的冰雪融化, 通过纳赤河、旺赤河、共比河和龙潭河等 四条河流注人湿地; 10 月份之后,气温骤降,冰雪冻结,水量大幅度减少. 另外,地下水是纳帕海湿地草甸的 重要水源, 中甸地下水资源较丰富, 并且由于纳帕海地势低洼以及周边环境喀斯特地貌发育, 因此, 纳帕海 湿地周围地区分布着大量的泉眼, 是草甸水源的重要补给源, 由于中甸地下水资源主要由降水以及地表径 流补给,因而汇人纳帕海草甸的地下水有着明显的季节变化特征.

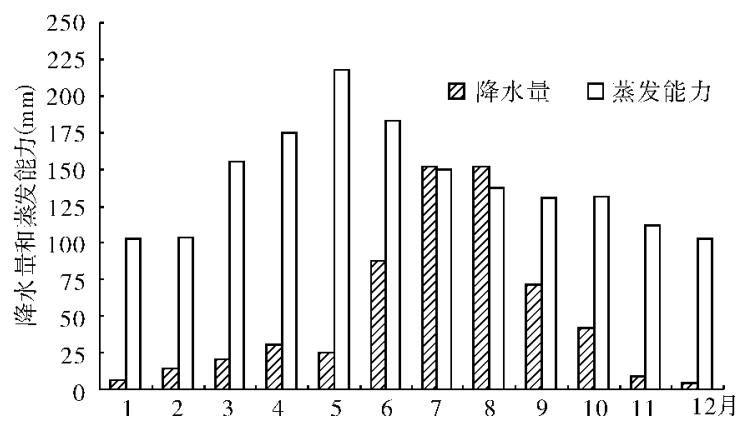

图 1 纳帕海湿地草甸降水和蒸发能力变化特征

Fig. 1 Characteristics of precipitation andevaporation in Napahai wetlands 
湿地水文周期是指湿地水位的时间格局, 它综合了湿地水量平衡的所有方面 ${ }^{[14,15]}$. 纳帕海湿地草甸区 域水文周期 (图 2), 受到降水、蒸发、冰雪融水以及地下水等诸多因素的影响,该区域水位变化显著. 6 月份 地下水位急剧上升, 到 8 月份, 源于赤道洋面的西南季风盛行, 阴雨天多, 降水相对丰富, 水面迅速扩大, 受 其影响, 负地貌较明显的区域呈水分过湿状态甚至出现积水现象. 由于纳帕海湿地发育在石灰岩母质的中 甸高原上, 喀斯特作用强烈, 其底部形成几个大落水洞, 水位退落迅速, 10 月份, 草甸地下水位降至 $35-$ $40 \mathrm{~cm}$ 左右, 10 月后雨季结束, 纳帕海步人枯水期,在温度最冷气候最干燥的 1 月份, 水位降至最低, 此时纳 帕海湿地为冰雪覆盖.

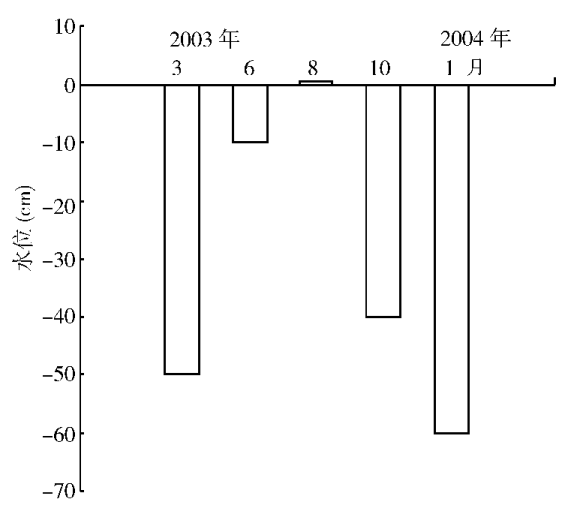

图 2 纳帕海湿地草甸水文周期变化特征

Fig. 2 Characteristics of hydrological periods in Napahai wetlands

\section{2 水文周期对草甸土壤有机质的影响}

水文周期对纳帕海湿地草甸土壤有机质的驱动作用在时间格局上差异显著 (表 1),3 月份时,草甸类 型湿地土壤的有机质处于相对较低水平. 6 月份, 雨季来临, 降水逐渐增多,周边高山山脚处的泉水水量增 大, 对草甸土壤有机质的淋溶携带作用加强, 加之该季地下水位较高, 使有机质在深层淀积, 这就是在 $0-$ $20 \mathrm{~cm}$ 表层的草甸土壤有机质含量减至 $32.67 \mathrm{~g} / \mathrm{kg}$ 而在 $20-40 \mathrm{~cm}$ 深层其含量增加至 $8.32 \mathrm{~g} / \mathrm{kg}$ 的缘故. 在 雨量最大的 8 月份, 草甸土壤水分过湿, 少数负地貌较明显的区域甚至积水, 水分达到饱和产生厌氧环境, 处于还原条件下有利于有机质的形成,加之此时通气状况较差有机物质的矿化分解程度微弱, 故 $0-20 \mathrm{~cm}$ 表层和 20-40 cm 深层草甸土壤有机质含量分别增至 $40.23 \mathrm{~g} / \mathrm{kg}$ 和 $8.69 \mathrm{~g} / \mathrm{kg} .10$ 月份, $0-20 \mathrm{~cm}$ 表层草甸 土壤有机质含量急剧下降, 其含量为 $36.67 \mathrm{~g} / \mathrm{kg}$, 在 $20-40 \mathrm{~cm}$ 深层草甸土壤中有机质含量降至 $7.74 \mathrm{~g} / \mathrm{kg}$, 主要原因是 8 月后湖水退落, 草甸区域水位急剧下降, 携带了大量的表层土壤中有机成分; 另外, 水位的下 降导致土壤水分含量减少, 土壤通气状况良好产生氧化环境, 有机质的矿化分解程度加强. 纳帕海湿地自 10 月即步人干旱寒冷的冬季, 草甸区域的草本植物均已枯死, 在草甸土壤中积累, 1 月份, 草甸区域地下水 位很低但地表被冰雪覆盖, 平均气温仅为 $-3.7^{\circ} \mathrm{C}$, 土壤冻结, 此时土壤微生物活性低、土温低以及土壤的通 气状况差导致土壤有机质矿化程度低, 土壤中有机质处于积累状态, 故该季 $0-20 \mathrm{~cm}$ 表层和 $20-40 \mathrm{~cm}$ 深 层草甸土壤有机质含量均达到其最高值, 分别为 $41.37 \mathrm{~g} / \mathrm{kg}$ 和 $8.83 \mathrm{~g} / \mathrm{kg}$.

表 1 纳帕海湿地草甸土壤有机质含量特征

Tab. 1 Characteristics of organic matters in the meadows in Napahai wetlands

\begin{tabular}{ccccccc}
\hline \multirow{2}{*}{} & \multirow{2}{*}{ 土层 } & \multicolumn{5}{c}{ 年月 } \\
\cline { 3 - 6 } $0-20 \mathrm{~cm}$ & 有机质含量 $(\mathrm{g} / \mathrm{kg})$ & 38.69 & 32.67 & 40.23 & 36.67 & 41.37 \\
& 变异系数 $(C V \%)$ & 35.43 & 29.34 & 21.42 & 4.80 & 31.45 \\
\multirow{2}{*}{$20-40 \mathrm{~cm}$} & 有机质含量 $(\mathrm{g} / \mathrm{kg})$ & 6.83 & 8.32 & 8.69 & 7.74 & 8.83 \\
& 变异系数 $(C V \%)$ & 30.98 & 11.46 & 21.52 & 28.04 & 14.71 \\
\hline
\end{tabular}




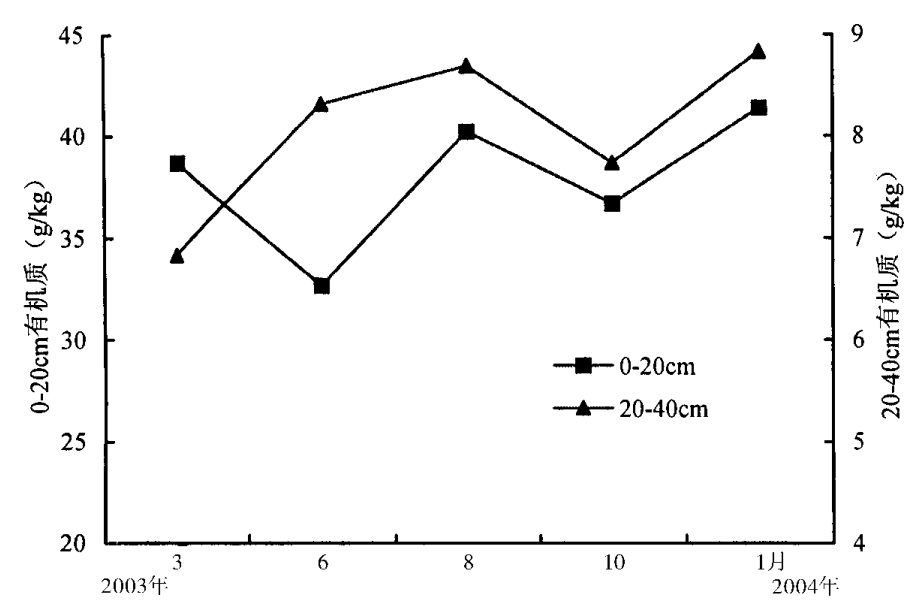

图 3 季节性水文周期驱动下的草甸土壤有机质含量变化特征

Fig. 3 Characteristics of wetlands soil organic matters under hydrological periods in Napahai wetlands

水文周期对纳帕海湿地表层和深层草甸土壤有机质变化的驱动作用显著 (图 3). 垂直空间上,表层草 甸土壤有机质含量明显高于深层土壤有机质的含量, 在 $0-20 \mathrm{~cm}$ 表层草甸土壤中有机质含量变化幅度为 $32.67-41.37 \mathrm{~g} / \mathrm{kg}$, 水文周期对其驱动效果呈不规则的 “ W” 型, 而水文周期对 $20-40 \mathrm{~cm}$ 深层草甸土壤的 驱动作用则为不规则的 “ $N$ ” 型多峰曲线变化, 其有机质含量的变化幅度则为 $6.83-8.83 \mathrm{~g} / \mathrm{kg}$.

\section{3 水文周期对草甸土壤有机质的驱动过程模拟}

为了描述水文周期与纳帕海湿地草甸土壤有机质含量变化之间的关系,根据在水文周期的驱动下草甸 土壤有机质含量变化的多峰动态曲线特征, 采用高斯多峰模型对其进行模拟并建立相应的数学模型, 拟合 参数如表 2 .

模型函数如 $(1)$ 式, 两土层的拟合优度 $\left(R^{2}\right)$ 分别为 0.9842 和 1 ,这表明水文周期对纳帕海湿地草甸土 壤有机质含量变化的驱动过程可以用高斯模型模拟, 结果理想, 并且 $20-40 \mathrm{~cm}$ 土层的拟合效果要优于 $0-$ $20 \mathrm{~cm}$ 土层. 因此, 高斯多峰模型能够理想地描述季节性水文周期对纳帕海湿地草甸土壤有机质含量变化 的驱动过程.

$$
\text { 模拟函数: } y=y_{0}+(A /(w \operatorname{sqrt}(\Pi / 2))) \exp \left(-2\left(\left(x-x_{c}\right) / w\right)^{2}\right)
$$

式中: $y_{0} 、 A 、 x_{c}$ 和 $w$ 为拟合方程参数, $x$ 为自变量, $y$ 为因变量.

表 2 水文周期对纳帕海湿地草甸土壤有机质的驱动过程模拟模型

Tab. 2 Simulating models of hydrology period driving on organic matters in Napahai wetlands

\begin{tabular}{|c|c|c|c|c|c|}
\hline \multirow{2}{*}{$\begin{array}{l}\text { 土层 } \\
(\mathrm{cm})\end{array}$} & \multicolumn{4}{|c|}{ 拟合方程参数 } & \multirow{2}{*}{ 拟合优度 $\left(R^{2}\right)$} \\
\hline & $y_{0}$ & $A$ & $x_{c}$ & $w$ & \\
\hline \multirow[t]{3}{*}{$0-20$} & 2.488 & 13.842 & -1.336 & 2.792 & 0.984 \\
\hline & & 6.937 & 3.308 & 0.765 & \\
\hline & & 4.702 & 4.870 & 0.529 & \\
\hline \multirow[t]{3}{*}{$20-40$} & 0.683 & 0.092 & 3.092 & 1.292 & 1 \\
\hline & & 0.147 & 2.242 & 0.662 & \\
\hline & & 0.287 & 4.923 & 1.437 & \\
\hline
\end{tabular}




\section{3 结论}

(1) 湿地水文周期是指水位变化的时间格局,受降水量、蒸发量、周围高山上的冰雪融水以及地下水等 水文要素的影响,纳帕海湿地草甸区域水位有着明显的季节性变化特征.

(2) 水文周期对纳帕海湿地草甸土壤有机质含量变化有着显著影响,但对不同土层土壤有机质的驱动 效果则各不同. 水文周期对 0-20 cm 表层草甸土壤有机质含量的变化影响呈不规则的 “W” 型, 而对 $20-$ $40 \mathrm{~cm}$ 深层土壤的驱动作用则为不规则的 “ $\mathrm{N}$ ” 型多峰曲线变化, 其驱动过程均可用高斯多峰模型进行模拟, 结果理想,能反映水文周期对纳帕海湿地草甸土壤有机质变化的驱动规律.

\section{4 参考文献}

[1] Mitsch W J, Gosselink J G. Wetlands. New York: John Wiley \& Sons, 2000:155 - 204.

[2] Mitsch W J, Gosselink J G. Wetlands. New York: Van Nostrand Reinhold Company Inc, 1986:89 - 125.

[3] 陈宜瑜. 湿地功能与湿地科学研究的方向. 中国基础科学, 2002,1:17-19.

[4] 田家怡,王秀凤,蔡学军等. 黄河三角洲湿地生态系统保护与恢复技术. 青岛: 中国海洋大学出版社, $2005: 10-22$.

[5] 何池全. 湿地植物生态过程理论及其应用: 三江平原典型湿地研究. 上海: 上海科学技术出版社, $2003: 87-90$.

[6] 安树青. 湿地生态工程: 湿地资源利用与保护的优化模式. 北京: 化学工业出版社,2003:43-45.

[7] 陆健健,何文珊,童春富等. 湿地生态学. 北京:高等教育出版社,2006:2 - 5,75-80.

[8] 田 昆, 常凤来,陆 梅等. 人为活动对云南纳帕海湿地土壤碳氮变化的影响. 土壤学报, 2004,41 (5) $: 681-686$.

[9] 田 昆,陆 梅, 常凤来等. 云南纳帕海岩溶湿地生态环境变化及驱动机制. 湖泊科学, 2004,16 (1): $35-42$.

[10］李宁云. 纳帕海湿地生态系统退化评价指标体系研究. 昆明:西南林学院,2006:38 - 43.

[11] 田 昆,陈宝昆, 贝荣塔. In-situ 方法在研究退化土壤氮库时空变化中的应用. 生态学报, 2003, 23 (9) :1937-1943.

[12]田昆, 常凤来, 莫剑锋等. 原状土就地培养取样法定位研究田间土壤氮动态变化. 植物营养与肥料 学报, 2004,10(2): 143-147.

[13] 中国科学院南京土壤研究所. 土壤理化分析. 上海: 上海科学技术出版社, 1978:132-135.

[14] 邓 伟,胡金明. 湿地水文学研究进展及科学前沿问题. 湿地科学, 2003,1(1):12 - 20 .

[15] Committee on characteristics of wetlands. Wetlands: Characteristics and Boundaries. Washington DC: National Academy press, 1995. 